\title{
CARACTERIZAÇÃO DA TRANSMISSÃO DO VÍRUS DO MOSAICO-DAS-NERVURAS DO ALGODOEIRO PELO PULGÃO APHIS GOSSYPII COM RELAÇÃO À PERSISTÊNCIA E AO TEMPO NECESSÁRIO PARA INOCULAÇÃO $\left({ }^{1}\right)$
}

\author{
MARCOS DONISETI MICHELOTTO $\left({ }^{*}\right)$; ANTONIO CARLOS BUSOLI $\left({ }^{3}\right)$
}

\begin{abstract}
RESUMO
Na cultura do algodoeiro, Gossypium hirsutum L., o pulgão Aphis gossypii Glover, 1877 (Hemiptera: Aphididae) destaca-se pela transmissão do vírus do mosaico-das-nervuras do algodoeiro. O objetivo deste trabalho foi avaliar a persistência da transmissão desse vírus por A. gossypii e determinar o período necessário para sua inoculação. No ensaio de persistência, 20 pulgões ápteros virulíferos foram individualizados e transferidos diariamente para plantas de algodoeiro sadias. O período necessário para inoculação foi determinado em adultos ápteros e alados virulíferos, que permaneceram confinados isoladamente em plantas sadias por períodos de 40 segundos, 45 minutos, 1,5 hora, 3, 6, 12, 24 e 48 horas. Observou-se que $35 \%$ dos pulgões transmitiram o vírus por mais de cinco plantas sucessivamente, no ensaio de persistência. Verificouse transmissão por um período máximo de 12 dias após a aquisição, o que caracteriza a relação vírus-vetor como persistente. Os adultos ápteros transmitiram o vírus para maior percentual de plantas $(75,0 \%)$ quando o período de acesso à inoculação foi de 24 horas. Os alados transmitiram o vírus em todos os períodos de acesso à inoculação, com porcentagens variando de 5,0\% (40 segundos) a 60,0\% (48 horas). A persistência da transmissão do vírus pelo pulgão e o aumento na eficiência de transmissão em função do aumento do período de acesso à inoculação revelam que a transmissão é do tipo circulativa.
\end{abstract}

Palavras-chaves: Gossypium hirsutum, Cotton leafroll dwarf virus, afídeo, interação vírus-vetor, doença azul.

\section{ABSTRACT \\ CHARACTERIZATION OF THE COTTON VEIN MOSAIC VIRUS BY APHIS GOSSYPII TRANSMISSION WITH RELATION TO PERSISTENCE AND TIME NECESSARY FOR INOCULATION}

In cotton crops (Gossypium hirsutum L.), the aphid Aphis gossypii Glover, 1877 (Hemiptera: Aphididae) is a major sanitary factor due forts efficiency on transmission of cotton vein mosaic virus (CVMV). The objective of this work was to evaluate the persistence of CVMV on transmission by A. gossypii and to determine the necessary feeding period for inoculation. In the persistence assay, individual aphids wingless viruliferous were separately transferred daily to successive series of healthy plants. The necessary period for inoculation was determined in individual winged and wingless adults viruliferous that were confined in healthy plants for different periods $(40 \mathrm{~s}, 45 \mathrm{~min}, 1.5 \mathrm{~h}, 3.0 \mathrm{~h}, 6.0 \mathrm{~h}, 12.0 \mathrm{~h}, 24.0 \mathrm{~h}$ and $48.0 \mathrm{~h}$ ). In the persistence assay, 35\% of total aphids transmitted the virus for more that five plants. Transmission for a maximum period of 12 days was verified after the acquisition, thus characterizing the relation virus-vector as persistent. The viruliferous wingless adults transmitted the virus from $1.50 \mathrm{~h}(5.0 \%$ of plants) and attain the maximum percentage in inoculation access period of the $24 \mathrm{~h}(75.0 \%)$. The viruliferous winged adults transmitted in all inoculation access periods, with maximum transmission in period of the $48 \mathrm{~h}(60.0 \%)$. The persistence mode of transmission of CVMV by aphid and the increased efficiency of transmission in function of increased inoculation access period suggest that the transmission of CVMV is indeed of circulative type.

Key words: Gossypium hirsutum, Cotton leafroll dwarf virus, aphid, virus-vector relationship, cotton blue disease.

$\left({ }^{1}\right)$ Recebido para publicação em 8 de maio de 2006 e aceito em 4 de abril de 2007.

$\left({ }^{2}\right)$ Agência Paulista de Tecnologia dos Agronegócios, Pólo Regional do Centro Norte, Rodovia Washington Luiz, km 372, 15800-000 Caixa Postal 24, Pindorama (SP). E-mail: michelotto@aptaregional.sp.gov.br $\left(^{*}\right)$ Autor correspondente.

$\left({ }^{3}\right)$ Universidade Estadual Paulista, Faculdade de Ciências Agrárias e Veterinárias, Departamento de Fitossanidade, Via de Acesso Prof. Paulo Donato Castellane, s/n, 14884-900 Jaboticabal (SP). E-mail: acbusoli@fcav.unesp.br. 


\section{INTRODUÇÃO}

O vírus do mosaico-das-nervuras do algodoeiro (VMNA) ou doença azul, como é comumente denominado, foi constatado pela primeira vez no Brasil em 1937, em algodoeiros plantados no Instituto Agronômico, em Campinas (COSTA e Forster, 1938). Em 1962/1963, foi detectada uma forma mais severa do vírus em algodoeiros do município de Ribeirão Bonito e, posteriormente, nos municípios de Dourado, Boa Esperança e Bocaina, no Estado de São Paulo, com potencial altamente destrutivo e sendo denominada forma "Ribeirão Bonito" (Costa et al., 1997). Recentemente, com o plantio de cultivares mais suscetíveis, o VMNA tem sido detectado com maior freqüência causando, em determinados casos, sérios prejuízos na Região Centro-Oeste (FreIre, 1999).

Os sintomas do VMNA consistem em redução do porte das plantas infectadas devido ao encurtamento dos entrenós, o que lhes dá a aparência mais compacta que o normal. Quando a infecção ocorre em planta parcialmente desenvolvida, observa-se o encurtamento dos entrenós apenas nos ponteiros, originando o sintoma denominado "topo compacto". Nas folhas das plantas afetadas, ocorrem mosaico nas nervuras, rugosidade e curvatura dos bordos para baixo. A forma Ribeirão Bonito provoca sintomas mais acentuados, reduzindo drasticamente o porte e desenvolvimento das plantas (Costa e CARvalHo, 1962).

A transmissão do VMNA é efetuada pelo pulgão Aphis gossypii Glover, 1877 (Hemiptera: Aphididae) (Cauquil, 1977; Cauguil e Follin, 1983; Costa et al., 1997). Por se tratar da mesma espécie vetora, além da semelhança dos sintomas do VMNA no Brasil, com os da "maladie bleue" e "enfermidad azul" que ocorrem, respectivamente, na África e Argentina, supõe-se que seja a mesma virose (ТАкIмото, 2003). Recentemente, CorrÊA et al. (2005) comprovaram que o agente causal da doença azul do algodoeiro ou VMNA é um vírus da família Luteoviridae, para o qual propuseram o nome Cotton Leafroll Dwarf Virus.

O conhecimento dos fatores que interferem na aquisição e transmissão do vírus pelo vetor é necessário para a compreensão das relações que envolvem a interação vírus-vetor-hospedeiro e conseqüentemente seu manejo (SWENSON, 1970). Para muitos vírus como, por exemplo, o vírus-do-nanismoamarelo-da-cevada (Barley Yellow Dwarf Virus BYDV), muitas dessas questões foram esclarecidas em vista dos grandes avanços ocorridos nos últimos anos (CostA, 1998). No entanto, para o VMNA poucos trabalhos foram realizados até o momento e dessa forma pouco se avançou na caracterização de sua transmissão pelo pulgão.
Em estudos de transmissão realizados na África, CAUQuIL e VAISSAYRE (1971) obtiveram eficiência de $60 \%$ a $100 \%$ das plantas de algodoeiro com os sintomas da "maladie bleue" após alimentação do pulgão A. gossypii. No Brasil, Michelotto e Busoli (2003a) observaram $77,8 \%$ e $95,6 \%$ das plantas de algodoeiro com os sintomas do VMNA transmitido por ninfas e adultos do pulgão respectivamente.

Este trabalho teve por objetivo caracterizar a transmissão do VMNA por A. gossypii com relação à persistência e ao tempo necessário para inoculação em plantas suscetíveis.

\section{MATERIAL E MÉTODOS}

Os ensaios de transmissão foram realizados em casa de vegetação, no Departamento de Fitossanidade da Faculdade de Ciências Agrárias e Veterinárias, Universidade Estadual Paulista, em Jaboticabal, Estado de São Paulo, Brasil, no ano agrícola de 2004/2005.

\subsection{Criação de manutenção dos pulgões virulíferos}

O VMNA empregado no estudo da interação vetor-patógeno foi obtido de plantas da cultivar CNPA ITA 90, considerada altamente suscetível (CIA e Fuzatto, 1999; Freire, 1999), originárias de plantio comercial da Estação Experimental da Fundação Chapadão no município de Chapadão do Sul, Estado de Mato Grosso do Sul, com os sintomas da doença (Figura 1). Os procedimentos utilizados foram semelhantes aos descritos por Michelotтo e Busoli (2003b), envolvendo o transplante das plantas infectadas para vasos de polietileno de $5 \mathrm{~L}$ isoladamente em gaiolas de estrutura metálica revestida por tela antiafídeo $(60 \mathrm{~cm}$ de diâmetro $x$ $120 \mathrm{~cm}$ de altura). Nessas plantas foram colocados exemplares de A. gossypii para se alimentarem e reproduzirem, oriundos de plantas de algodoeiro, cultivar DeltaOpal, resistente ao vírus (CIA e FuzATto, 1999), do Campus da FCAV/UNESP, em Jaboticabal (SP).

\subsection{Ensaio de persistência da transmissão do VMNA por A. gossypii}

O ensaio foi iniciado com a semeadura da cultivar CNP ITA 90 em recipientes de polietileno de $500 \mathrm{~mL}$ contendo uma mistura de solo, vermiculita e esterco (2:2:1). Optou-se pela utilização dessa cultivar como planta-teste, por sua alta suscetibilidade ao VMNA (Cia e FuZATto, 1999) e rápida expressão dos sintomas, sendo possível observá-los a partir de 20 dias após a transmissão (Michelotto e Busoli, 2003a). 
Após a germinação das plântulas, foi realizado um desbaste, mantendo-se apenas uma planta-teste por recipiente. Essas plantas, ao atingirem um par de folhas verdadeiras desenvolvidas (15 dias após a emergência), receberam um pulgão adulto áptero da criação de manutenção. Esse pulgão permaneceu confinado isoladamente em uma pequena gaiola, formada por um cilindro de plástico incolor de $4 \mathrm{~cm}$ de diâmetro e $1 \mathrm{~cm}$ de altura, com a extremidade superior fechada com "voile" e a outra fixada à folha por uma presilha de metal (Figura 2), por um período de acesso à inoculação (PAI) de 24 horas. Após esse período, os pulgões foram transferidos para novas plantas-teste e novo PAI de 24 horas, e assim sucessivamente até que ocorresse a morte do pulgão. Neste estudo, foram utilizados 20 pulgões adultos ápteros da criação de manutenção.

Após as transferências e a morte dos pulgões virulíferos, as plantas-teste foram pulverizadas com inseticida endosulfan (Thiodan ${ }^{\circledR} 350 \mathrm{CE}$ ) na dose de 1,5 L.ha ${ }^{-1}$ de p.c. para eliminar e evitar a ocorrência de pulgões e/ou outros insetos indesejáveis. Essas plantas foram isoladas em casa-de-vegetação para a expressão ou não dos sintomas da doença. Decorridos 60 dias após a morte do último pulgão, tempo mais que suficiente para a exteriorização dos sintomas do VMNA nas plantas contaminadas (Michelotto e Busoli, 2003a), determinou-se a porcentagem de plantas sintomáticas.

Para melhor caracterização de uma possível relação entre as percentagens (diária e acumulada) de transmissão por A. gossypii e o tempo após a aquisição do VMNA em plantas infectadas, realizou-se uma análise de Regressão Polinomial, determinando-se as curvas mais ajustadas e os respectivos coeficientes de determinação $\left(R^{2}\right)$.

\subsection{Ensaio de diferentes períodos de acesso à inoculação do VMNA.}

Este ensaio foi realizado em plantas-testes semeadas em vasos, como no ensaio anterior e sob estufa telada. Foi iniciado quando havia nas plantas um par de folhas verdadeiras, transferindo-se para cada planta, com o auxílio de pincel, um pulgão áptero ou um alado virulífero da criação e desta forma não houve controle do período de acesso à aquisição do vírus (PAA). Os pulgões permaneceram nas folhas, confinados em pequenas gaiolas (Figura 2).

Em função da ausência de dados na literatura brasileira, relacionados com o período de acesso à inoculação (PAI) necessário para que os pulgões fossem capazes de transmitir o VMNA, os períodos foram definidos baseando-se em trabalhos realizados por Gill (1970), Sylvester (1980) e Cupertino et al. (1995). Os períodos (tratamentos) definidos foram: 40 segundos (simulando "picada de prova" do inseto), 45 minutos, 1,5 h, 3, 6, 12, 24 e 48 horas, com 20 pulgões ápteros e alados por tratamento. Após cada PAI, os pulgões foram eliminados manualmente e as plantas-teste foram pulverizadas com inseticida endosulfan (Thiodan ${ }^{\circledR} 350 \mathrm{CE}$ ) na dose de 1,5 $\mathrm{L} \mathrm{ha}^{-1}$ de p.c. e mantidas em casa-de-vegetação para a expressão dos sintomas da doença.

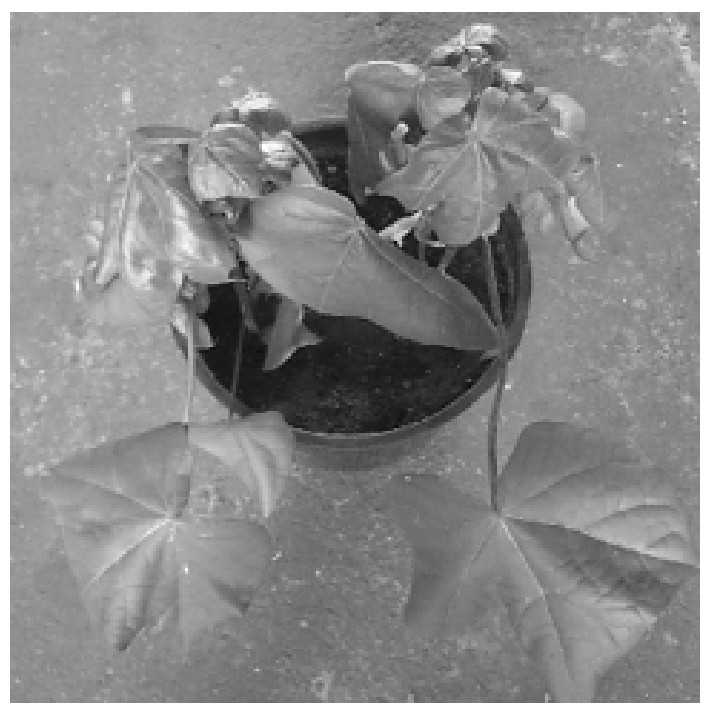

Figura 1. Plantas com os sintomas do VMNA.

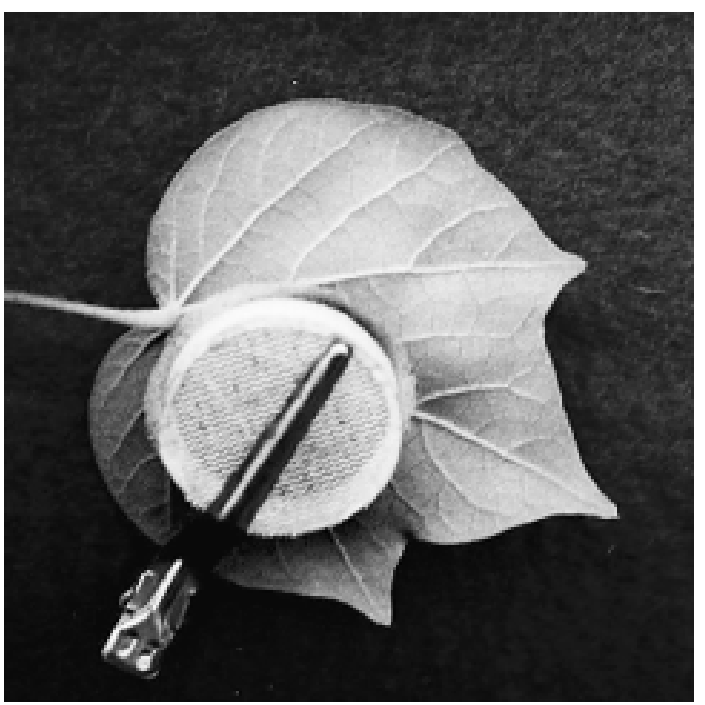

Figura 2. Detalhe da gaiola utilizada para confinamento do pulgão. 
Decorridos 60 dias após os PAI's (Michelotto e Busoli, 2003a), realizou-se a contagem de plantas de algodoeiro com os sintomas do VMNA, e determinouse a percentagem de transmissão. As taxas de transmissão obtidas nas 20 plantas de cada tratamento (PAI) para pulgões ápteros e alados foram comparadas pelo teste de Qui-quadrado $\left(\chi^{2}\right)$, ao nível de $5 \%$ de probabilidade de erro. Para caracterizar a relação entre a porcentagem de transmissão do VMNA e a duração do PAI, realizou-se análise de Regressão Polinomial, determinando-se as curvas mais ajustadas e os respectivos coeficientes de determinação $\left(R^{2}\right)$.

\section{RESULTADOS E DISCUSSÃO}

\subsection{Persistência da transmissão do VMNA}

Observou-se que 14 pulgões (70\%) transmitiram o VMNA a pelo menos uma planta (Tabela 1). Michelotto e Busoli (2003a), em ensaio de eficiência de transmissão desse vírus por A. gossypii, observaram que após um PAI de 48 horas para ninfas e 24 horas para adultos ápteros, respectivamente, em $77,8 \%$ e $95,6 \%$ das plantas da cultivar CNPA ITA 90 ocorreram sintomas do VMNA.

O maior número de plantas infectadas por um mesmo pulgão foi de 11 plantas, e não sucessivas, porque na $6 .^{a}$ planta que recebeu o mesmo pulgão não houve sintomas; da $7 .^{a}$ até $12 .^{a}$ transferência diária, ocorreram sintomas nas plantas (Tabela 1). O maior percentual de transmissão foi obtido aos dois dias após a aquisição, isto é, após a transferência dos pulgões para as segundas plantas, com $65 \%$ das 20 plantas. O PAA e a idade dos pulgões, que não foram controlados neste estudo, podem ter influenciado na eficiência de transmissão do vírus, uma vez que os pulgões usados no teste foram coletados ao acaso da criação de manutenção. Rochow (1959) realizou ensaio semelhante ao alimentar pulgões em plantas infectadas por BYDV por diferentes PAA, e verificou que os pulgões que se alimentaram de plantas infectadas por 72 horas transmitiram o vírus para o maior número de plantas em sucessão, enquanto para pulgões que adquiriram o vírus por 1 hora transmitiram apenas ocasionalmente. Dessa forma, os pulgões dependem da quantidade de vírus que adquiriram para realizar a transmissão. Gill (1970), realizando ensaio semelhante com BYDV e seu vetor, o pulgão Rophalosiphum maidis Fitch, porém com idade conhecida do vetor, observou enorme variação na transmissão do vírus, tanto por ninfas, quanto por adultos.

A eficiência de transmissão do VMNA foi diminuindo após transferências sucessivas para plantas-testes, seguindo um modelo linear (Figura 3).
Já a curva ajustada entre a porcentagem acumulada e a transferência diária seguiu um modelo cúbico; o maior número de plantas com sintomas do vírus ocorreu até o $8 .^{\circ}$ dia, observando-se transmissão até, no máximo, a $12 .^{\circ}$ dia (Tabela 1 e Figura 3 ).

Do total de pulgões utilizados, $6(30 \%)$ transmitiram o vírus até a sua morte, mesmo após mais de cinco dias alimentando-se de plantas sadias diferentes, corroborando as afirmações de CAuQuil e Follin (1983), Costa et al. (1997) е ТАКімото (2003) de que a transmissão do VMNA pelo pulgão A. gossypii é do tipo circulativa, que se caracteriza pela retenção da infectividade por um período de vários dias após o término da aquisição do vírus em plantas infectadas.

\subsection{Eficiência de transmissão em diferentes períodos de acesso à inoculação}

O VMNA foi transmitido tanto por ápteros quanto por alados de A. gossypii, porém em proporções diferentes. Os pulgões ápteros transmitiram o vírus a partir do PAI de $1,50 \mathrm{~h}$, com $5,0 \%$ de eficiência (Tabela 2). Esta porcentagem atingiu seu máximo quando os ápteros tiveram um PAI de 24 horas, e 75,0\% das plantas com sintomas da doença. Através da análise de Regressão Polinomial entre a porcentagem de transmissão do VMNA e a duração dos PAI's, observou-se que a curva mais ajustada foi a quadrática (Figura 4), em que o aumento do período de inoculação resultou em aumento da percentagem de transmissão até aproximadamente 30 horas.

Alados de A. gossypii transmitiram o VMNA em todos os períodos de acesso, com percentagens crescentes, variando de 5,0\% (40 segundos) a $60,0 \%$ (48 horas) (Tabela 2). No entanto, os tratamentos com PAI's de 6 até 48 horas não diferiram na eficiência de transmissão. A curva mais ajustada para a regressão entre os PAI's e eficiência de transmissão do VMNA por alados também seguiu o modelo quadrático (Figura 4), observando-se que no intervalo estudado, ocorreu um aumento na eficiência de transmissão com o incremento do período de acesso à inoculação até próximo de 42 horas. Uma das características dos vírus pertencentes à família Luteoviridae é a necessidade de um período de inoculação pelo vetor superior a 15 minutos para sua transmissão (Hull, 2001). No entanto, a transmissão do VMNA por um pulgão alado através da "picada de prova" assemelhou-se aos vírus de transmissão não persistentes.

WATson e Mulligan (1960) observaram uma relação positiva entre o PAA e o PAI de BYDV pelo pulgão $R$. maidis, na qual as maiores transmissões 
foram verificadas para os maiores períodos. No entanto, considerando apenas o PAA de 48 horas, não se verificou diferença na eficiência transmissão para os diferentes PAI's utilizados, notando-se que o PAA do vírus pelo pulgão reflete na eficiência de transmissão independentemente do PAI.

Quando os resultados de transmissão por ápteros e alados foram analisados em conjunto, observou-se que as maiores percentagens de transmissão ocorreram entre 24 e 48 h de PAI, com $62,5 \%$ e $55,0 \%$ das plantas com sintomas, respectivamente (Tabela 2). ТАКімото (2003), trabalhando com a mesma espécie de pulgão e vírus, não observou plantas infectadas nas diferentes densidades de pulgões utilizadas $(1,3,9$ e 27) com PAI de 15 e 60 minutos, sugerindo que a transmissão seja do tipo circulativa. Zhou e Rochow (1984) observaram um aumento na transmissão de BYDV por Schizaphis graminum Rondani em função do aumento nos períodos de aquisição e inoculação do vírus e que esses aumentos na transmissão podem estar relacionados com a possível existência de um período latente envolvido na transmissão do BYDV pelo pulgão. CUPERTiNo et al. (1995), trabalhando com o vírus-do-enrolamento-da-folha-da-batata (PLRV), transmitido pelo pulgão Myzus nicotianae Blackman, também observaram maior eficiência na transmissão do vírus em maiores PAA e PAI .

Tabela 1. Persistência da transmissão do VMNA em adultos ápteros de Aphis gossypii em períodos sucessivos de acesso à inoculação de $24 \mathrm{~h}$ em plantas de algodoeiro (Cultivar CNPA ITA 90)

\begin{tabular}{|c|c|c|c|c|c|c|c|c|c|c|c|c|c|c|c|c|c|}
\hline \multirow{2}{*}{$\begin{array}{l}\text { Pulgões } \\
\text { (Repetições) }\end{array}$} & \multicolumn{16}{|c|}{ Plantas e dias sucessivos de inoculação } & \multirow{2}{*}{ Total $\left({ }^{1}\right)$} \\
\hline & $1^{\mathrm{a}}$ & $2^{\mathrm{a}}$ & $3^{\mathrm{a}}$ & $4^{\mathrm{a}}$ & $5^{a}$ & $6^{a}$ & $7^{\mathrm{a}}$ & $8^{\mathrm{a}}$ & $9^{a}$ & $10^{\mathrm{a}}$ & $11^{\mathrm{a}}$ & $12^{\mathrm{a}}$ & $13^{\mathrm{a}}$ & $14^{\mathrm{a}}$ & $15^{\mathrm{a}}$ & $16^{\mathrm{a}}$ & \\
\hline 1 & + & + & + & + & + & - & + & + & + & + & + & + & - & - & & & $11 / 14$ \\
\hline 2 & + & + & + & + & - & + & + & + & - & + & & & & & & & $8 / 10$ \\
\hline 3 & + & + & + & - & + & + & - & + & + & - & - & & & & & & $7 / 10$ \\
\hline 4 & + & + & + & + & + & + & - & + & & & & & & & & & $7 / 8$ \\
\hline 5 & + & + & + & + & - & + & + & + & & & & & & & & & $7 / 8$ \\
\hline 6 & + & + & + & - & + & + & & & & & & & & & & & $5 / 6$ \\
\hline 7 & - & + & + & + & + & + & & & & & & & & & & & $5 / 6$ \\
\hline 8 & + & + & - & - & + & + & - & - & & & & & & & & & $4 / 8$ \\
\hline 9 & - & + & + & + & + & & & & & & & & & & & & $4 / 5$ \\
\hline 10 & + & + & - & - & + & - & - & & & & & & & & & & $3 / 7$ \\
\hline 11 & + & + & - & - & - & & & & & & & & & & & & $2 / 5$ \\
\hline 12 & + & + & - & - & & & & & & & & & & & & & $2 / 4$ \\
\hline 13 & - & - & - & + & - & - & & & & & & & & & & & $1 / 6$ \\
\hline 14 & - & + & - & - & - & & & & & & & & & & & & $1 / 5$ \\
\hline 15 & - & - & - & - & - & - & - & - & - & - & - & - & - & - & - & - & $0 / 16$ \\
\hline 16 & - & - & - & - & - & - & - & - & - & - & - & - & & & & & $0 / 12$ \\
\hline 17 & - & - & - & - & - & - & - & - & - & - & & & & & & & $0 / 10$ \\
\hline 18 & - & - & - & - & - & - & - & - & - & & & & & & & & $0 / 9$ \\
\hline 19 & - & - & - & - & - & - & & & & & & & & & & & $0 / 6$ \\
\hline 20 & - & - & - & - & - & & & & & & & & & & & & $0 / 5$ \\
\hline $\begin{array}{l}\text { Plantas com } \\
\text { sintomas (\%) }\end{array}$ & 50 & 65 & 40 & 35 & 40 & 44 & 27 & 50 & 29 & 33 & 25 & 33 & 0 & 0 & 0 & 0 & 37,5 \\
\hline
\end{tabular}

+ plantas com os sintomas do VMNA; - plantas sem os sintomas do VMNA.

(1) Número de plantas com vírus / número de plantas inoculadas. 
Tabela 2. Percentagem de transmissão do VMNA após diferentes períodos de acesso à inoculação em plantas de algodoeiro (cultivar CNPA ITA 90) por adultos ápteros e alados de Aphis gossypii

\begin{tabular}{|c|c|c|c|}
\hline \multirow{2}{*}{ Períodos de acesso à inoculação } & \multicolumn{3}{|c|}{ Plantas com sintomas } \\
\hline & Ápteros & Alados & Ambos \\
\hline & & $\%$ & \\
\hline \multirow[t]{2}{*}{40 segundos } & $0,0 \mathrm{a}$ & $5,0 \mathrm{a}$ & $2,5 \mathrm{a}$ \\
\hline & $(0 / 20)\left({ }^{1}\right)$ & $(1 / 20)$ & $(1 / 40)$ \\
\hline \multirow[t]{2}{*}{45 minutos } & $0,0 \mathrm{a}$ & $10,0 \mathrm{ab}$ & $5,0 \mathrm{a}$ \\
\hline & $(0 / 20)$ & $(2 / 20)$ & $(2 / 40)$ \\
\hline \multirow[t]{2}{*}{1,5 hora } & 5,0 a & $10,0 \mathrm{ab}$ & $7,5 \mathrm{a}$ \\
\hline & $(1 / 20)$ & $(2 / 20)$ & $(3 / 40)$ \\
\hline \multirow[t]{2}{*}{3 horas } & $40,0 \quad b$ & $25,0 \mathrm{abc}$ & $32,5 \mathrm{~b}$ \\
\hline & $(8 / 20)$ & $(5 / 20)$ & $(13 / 40)$ \\
\hline \multirow[t]{2}{*}{6 horas } & $40,0 \mathrm{~b}$ & $30,0 \mathrm{bcd}$ & $35,0 \mathrm{~b}$ \\
\hline & $(8 / 20)$ & $(6 / 20)$ & $(14 / 40)$ \\
\hline \multirow[t]{2}{*}{12 horas } & $35,0 \mathrm{~b}$ & $35,0 \mathrm{bcd}$ & $35,0 \mathrm{~b}$ \\
\hline & $(7 / 20)$ & $(7 / 20)$ & $(14 / 40)$ \\
\hline \multirow[t]{2}{*}{24 horas } & $75,0 \mathrm{c}$ & $50,0 \mathrm{~cd}$ & $62,5 \mathrm{c}$ \\
\hline & $(15 / 20)$ & $(10 / 20)$ & $(25 / 40)$ \\
\hline \multirow[t]{2}{*}{48 horas } & 50,0 bc & $60,0 \mathrm{~d}$ & $55,0 \mathrm{c}$ \\
\hline & $(10 / 20)$ & $(12 / 20)$ & $(22 / 40)$ \\
\hline Teste $\chi^{2}$ & $47,73^{* *}$ & $28,17^{* *}$ & $69,84^{* *}$ \\
\hline
\end{tabular}

Porcentagens seguidas de mesma letra na coluna não diferem significativamente entre si pelo teste de $\chi^{2}$ a $5 \%$ de probabilidade de erro; ** Significativo a $1 \%$ de probabilidade.

(1) Número de plantas com sintomas / número de plantas inoculadas.

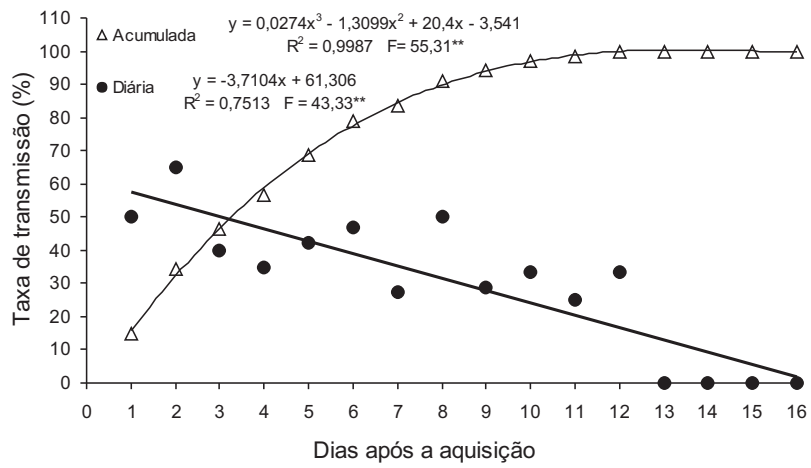

Figura 3. Curvas ajustadas para a regressão polinomial entre a percentagem diária $(\bullet)$ ou acumulada $(\Delta)$ de transmissão do VMNA por adultos ápteros de Aphis gossypii e o tempo (dias) após a aquisição em plantas infectadas.

** significativo a $1 \%$ de probabilidade de erro.

No presente trabalho, a maior eficiência na transmissão do VMNA por adultos ápteros e alados de A. gossypii obtida com o aumento dos períodos de acesso à inoculação, sugerindo que o vírus deve ser inoculado no floema, demandando períodos prolongados de acesso à inoculação para que o pulgão atinja o floema e passe a inocular o vírus, indicando ser uma transmissão do tipo circulativa. No entanto, vale salientar que essa transmissão poderia

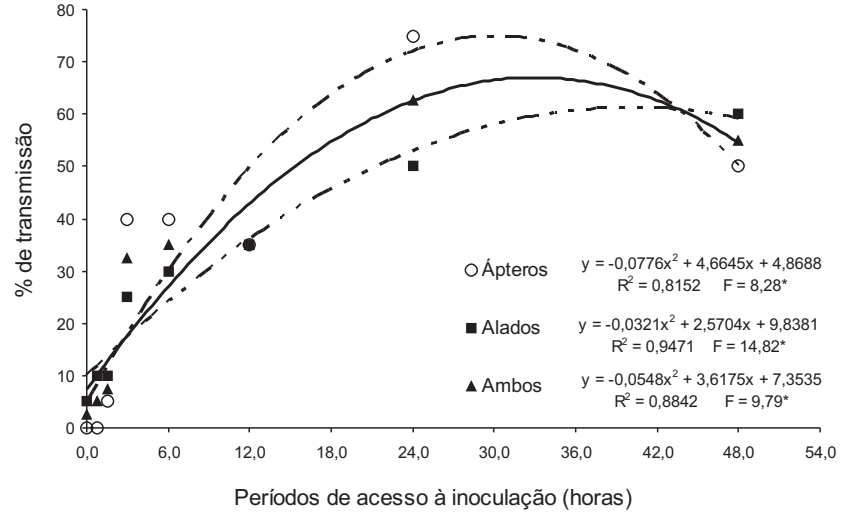

Figura 4. Curva ajustada para a regressão polinomial entre a porcentagem de transmissão do VMNA e os diferentes períodos de acesso à inoculação por adultos do pulgão-do-algodoeiro: ápteros (o), alados (•) e ambos $(\mathbf{\Lambda})$.

( ${ }^{*}$ significativo a $5 \%$ de probabilidade de erro).

ser do tipo semipersistente/não circulativa. Segundo Ng e Perry (2004), a transmissão do vírus do tipo circulativa necessita de períodos de acesso à inoculação variando de horas a dias para que se obtenha maior eficiência. SYLVESTER (1980) destaca que na transmissão circulativa, tanto a eficiência de aquisição, quanto de inoculação aumentam com o incremento do período de acesso à aquisição ou inoculação do vírus. 


\section{CONCLUSÕES}

1. A transmissão do VMNA por A. gossypii persiste por vários dias após a aquisição revelando ser a relação com o vetor do tipo circulativa.

2. O VMNA é mais eficientemente transmitido por ápteros e alados do pulgão quando mantidos por um PAI 24 horas em plantas da cultivar suscetível CNPA ITA 90.

3. O aumento na eficiência da transmissão do VMNA por adultos ápteros e alados de A. gossypii com o incremento dos PAI's representa uma evidência adicional de que a transmissão desse vírus pelo vetor é do tipo circulativa.

\section{AGRADECIMENTO}

Os autores agradecem à CAPES (Coordenação de Aperfeiçoamento de Pessoal de Nível Superior) pela bolsa de doutorado concedida ao primeiro autor.

\section{REFERÊNCIAS}

CAUQUIL, J. Estudes ser une maladie d'origine virale du cotonnier: la maladie bleue. Coton et Fibres Tropicales, Paris, v.32, n.3, p.259-278, 1977.

CAUQUIL, J.; FOLLIN, J.C. Presumed virus and mycoplasmalike organism diseases in subsaharan Africa and the rest of the world. Coton et Fibres Tropicales, Paris, v.38, n.4, p.293317,1983

CAUQUIL, J.; VAISSAYRE, M. La "maladie bleue" du cotonier en Afrique: transmission de cotonnier a cotonnier par Aphis gossypii Glover. Coton et Fibres Tropicales, Paris, v.26, n.3, p.463-466, 1971.

CIA, E.; FUZATTO, M.G. Manejo das doenças na cultura do algodão. In: CIA, E.; FREIRE E.C.; SANTOS, W.J. (Ed.). Cultura do algodoeiro. Piracicaba: Potafós, 1999. p.121-131.

CORRÊA, R.L.; SILVA, T.F.; SIMÕES-ARAÚJO, J.L.; BARROSO, P.A.V.; VIDAL, M.S.; VASLIN, M.F.S. Molecular characterization of a virus from the family Luteoviridae associated with cotton blue disease. Archives of Virology, Viena, v.150, n.7, p.1357-1367, 2005.

COSTA, A.S.; CARVALHO, A.M.B. Moléstias de vírus do algodoeiro. Bragantia, Campinas, v.21, p.45-62, 1962.

COSTA, A.S.; FORSTER, R. Nota preliminar sobre uma nova moléstia de vírus do algodoeiro - mosaico das nervuras. Revista de Agricultura, Piracicaba, n.3-4, p.187-191, 1938.

COSTA, A.S.; JULIATTI, F.C.; RUANO, O. Algodão (Gossypium hirsutum L.): doenças causadas por vírus. In: DO VALE, F.X.R.; ZAMBOLIM, L. (Ed.). Controle de Doenças de Plantas: grandes culturas. Viçosa: UFV, 1997. p.571-582.
COSTA, C.L. Vetores de vírus de plantas - 1. Insetos. In: LuZ, Q.C. (Ed.). Revisão anual de patologia de plantas. Passo Fundo, 1998. v.6. p.103-171.

CUPERTINO, F.P.; DUSI, A.N.; AVILA, A.C.; COSTA, C.L.; SILVA, A.M.R.; BUSO, J.A. Transmissão do vírus do enrolamento da folha da batata pelo pulgão vermelho do fumo, Myzus nicotiniae. Fitopatologia Brasileira, Brasília, v.20, n.3, p.440-443, 1995.

FREIRE, E.C. Doença azul tem solução. Cultivar, Pelotas, v.1, p.64-65, 1999.

GILL, C.C. Aphid nymphs transmit an isolate of barley yellow dwarf virus more efficiently than do adults. Phytopathology, Saint Paul, v.60, p.1747-1752, 1970.

HULL, R. Matthews' Plant Virology. San Diego: Academic Press, 2002. $1001 \mathrm{p}$

MICHELOTTO M.D.; BUSOLI A.C. Eficiência de ninfas e adultos de Aphis gossypii Glov. na transmissão do vírus do mosaico das nervuras do algodoeiro. Bragantia, Campinas, v.62, n.2, p.255-259, 2003a.

MICHELOTTO, M.D.; BUSOLI, A.C. Aspectos biológicos de Aphis gossypii Glover, 1877 (Hemiptera: Aphididae) em três cultivares de algodoeiro e em três espécies de plantas daninhas. Ciência Rural, Santa Maria, v.33, n.6, p.999-1004, 2003b.

NG, J.C.K.; PERRY, K.L. Transmission of plant viruses by aphid vectors. Molecular Plant Pathology, Oxford, v.5, n.5, p.505$511,2004$.

ROCHOW, W.F. Transmission of strains of barley yellow dwarf virus by two aphid species. Phytopathology, Saint Paul, v.49, p.744, 1959 .

SWENSON, K.G. Role of aphids in the ecology of plants viruses. Annual Review of Phytopathology, Saint Paul, v.6, p.1747$1752,1970$.

SYLVESTER, E.S. Circulative and propagative virus transmission by aphids. Annual Review of Entomology, Palo Alto, v.25, p.257-286, 1980.

TAKIMOTO, J.K. Estudo da relação vetor-patógenohospedeiro para a doença azul do algodoeiro. 2003. 97p. Dissertação (Mestrado) - Instituto Agronômico, Campinas.

WATSON, M.A.; MULLIGAN, T. The manner of transmission of some barley yellow-dwarf viruses by different aphid species. Annals of Applied Biology, Wellesbourne, v.48, p.711-720, 1960.

ZHOU, G.; ROCHOW, W.F. Differences among five stages of Schizaphis graminum in transmission of a barley yellow dwarf luteovirus. Phytopathology, Saint Paul, v.74, p.1450-1453, 1984. 